\title{
Hollywood'da Kostüm Tasarımının Ortaya Çıkışı: Travis Banton
}

Prof. Elvan ÖZKAVRUK ADANIR

İzmir Ekonomi Üniversitesi, GSTF

Tekstil ve Moda Tasarımı Bölümü

elvan.ozkavruk@ieu.edu.tr

ORCID: 0000-0003-2821-6412
Geliş Tarihi/Received: 31.01 .2021 Kabul Tarihi/Accepted: 10.07.2021 DOI: 10.46372 /arts.907557

\section{Öz}

Giysiler belli toplumlarda günlük yaşamın vazgeçilmez bir parçası olarak görülür. Dolayısıyla sinema öykülerinde kimliklerin oluşturulmasında en önemli ögelerden biri giysilerdir. Sinemada giysiler sadece karakter inşasında değil, aynı zamanda toplumsal cinsiyet rollerinin beden üzerinde inşasında da önemli bir rol oynar. Geçtiğimiz yüzyıldan günümüze filmlerde kullanılacak kostümlerin hazırlanması öneminden bir şey kaybetmemiş, ancak üretim şekli oldukça değişmiştir. İlk çekilen filmlerde kullanılan kostümlerin seçiminin gelişigüzel olduğunu söylemek mümkündür. Bu dönemde aktrisler ve aktörler filmlerde giyecekleri kıyafetleri kendi gardıroplarında bulunan giysilerinden seçmişlerdir. Tarihi giysilere intiyaç duyulduğunda ise Broadway'deki tiyatroların kostümleri kiralanmıştır. Bu çalışmada Hollywood sinemasında kostüm tasarımcılarının rolünün zamanla nasıl önem kazandığına odaklanılacaktır. Ayrıca yıllardır kostüm tasarımcılarına ilham veren 1930'lu yılların en önemli kostüm tasarımcılarından Travis Banton üzerinde durulacaktır. 1930'lu yıllarda halk karşısında daha feminen görünen film yıldızlarının yanı sıra, Marlene Dietrich gibi zaman zaman erkeksi bir imajı tercih eden yıldızların kostümleri ile ilgili literatür ve arşiv çalışmalarından örnekler verilerek görseller üzerinden kadın imgesi tartışılacaktır.

Anahtar Kelimeler: kostüm tasarımı, hollywood sineması, kostüm Tasarımcısı, travis banton, marlene dietrich 


\title{
Flourishing of Costume Design in Hollywood: Travis Banton
}

\begin{abstract}
Clothes are considered as mere accessories in daily life for certain societies. In that sense, they are one of the key elements to construct identities. Dresses used in cinema do not only acquire significance to shape the character but also they are in relation with the gender to construct the body. The preparation of costumes to be used in movies has not lost its importance since the last century, but production methods have been changed. It is also possible to say that the selection of the costumes used in the movies were done casually at first. During this period, actresses and actors chose their clothes they would wear in movies from their own wardrobes. When historical clothing was needed, costumes of Broadway theaters were rented. This study will focus on how the role of costume designers has gained importance over time in Hollywood cinema. Moreover, Travis Banton one of the most important costume designers of 1930s, who has inspired costume designers for years, will be emphasized. In the 1930's, besides movie stars who appeared more feminine publicly, there were few who preferred a masculine image like Marlene Dietrich from time to time. The image of women will be discussed through visuals, literature review and archive materials.
\end{abstract}

Keywords: costume design, hollywood cinema, costume designer, travis banton, marlene dietrich 


\section{Gíriş}

Moda tarihinde giysiler belli bir zamanı işaret ettiği kadar o dönemin kültürel ilgi alanlarını ve tercihlerini de anlatır. Bu anlamda giysiler, kimlik ve sosyal değişimini oluşturan ve bunu yaparken anlamlar da yaratan bir işaret sistemi olarak görülmektedir. Bu sebeple giysilerin toplumun normlarını ve cinsiyet rollerini de biçimleyen bir güce sahip olduğu söylenebilir. Özellikle sinemanın moda ile el ele gittiği dönemlerde toplumun yaygın bir kesimi filmlerde gördüğü giysileri, neredeyse birebir kendi giysilerine uyarlamış ve cinsiyet rollerinin de bu anlamda biçimlenmesinde etkili olmuştur. Bu çalışma kapsamında özellikle üzerinde durulacak dönem olan 1930'lu yıllar, kadınların yeni beden imajlarının dönüşümünde oldukça dikkat çekici bir yere sahiptir. 1920'li yılların erkeksi, "a la garçonne" görünümlü kadınları bir anda yeniden kadınsı beden siluetlerine geçiş yapmıştır. Bu geçişte filmlerde givilen kostümlerin de rol oynadığı söylenebilir. O dönemde Marlene Dietrich gibi zaman zaman daha erkeksi bir görünümü tercih eden yıldızlar da olmuştur. Bu iki ayrı keskin uç, moda tarihinin unutulmaz Hollywood şıklığı akımı ile daha da belirginleşmiştir.

Seyircilerin bir kısmı sinema perdesinde izlediği karakterin giysilerinden etkilenerek ona benzer bir imaja sahip olmak ister. Film yıldızının giydiği bir giysi, kullandığı bir aksesuar, saç modeli veya makyajı bir anda moda haline gelerek milyonlarca kişi tarafından kullanılmaya başlanır. Film yıldızlarını giydiren kostüm ve moda tasarımcıları olmadan modanın bu kadar hızla yayılamayacağı bir gerçektir (Engelmeier ve Engelmeier, 1990, s. 7). 1930'lu yıllarda sinemanın etkisinin güçlenmesi ve Hollywood'un kadın imgesi üzerindeki etkisi ile Hollywood'un bir nevi moda merkezine dönüştüğünü söylemek mümkündür. Birçok Avrupalı moda tasarımcısı da Hollywood'un bu özelliğine katkıda bulunmuştur. Kostüm tasarımcısı Travis Banton'ın tasarımları olmadan Marlene Dietrich belki de o göz alıcı cazibeye ya da kendisi ile özdeşleşen giyim tarzına sahip olmayabilirdi. Rita Hayworth'ın Şeytanın Kızı Gilda (Gilda, Charles Vidor, 1946) filminde Put the Blame on Mame şarkısını söylerken giydiği, ünlü Fransız moda tasarımcısı Jean Lovis'nin tasarladığı straplez elbise döneme damgasını vuran giysilerden biriydi. Fransız moda tasarımcısı Hubert de Givenchy de uzun yllar Audrey Hepburn'u hem filmlerde hem de özel hayatında giydirmişti (Berg ve Engelmeier, 1990, s. 19).

Bu çalışmada Hollywood sinemasının başlangıcından 1940'lı yıllara kadar kostüm tasarımcılarının modaya etkisi üzerinde durulacaktır. 1930'lu yıllarda feminen görünümleri içinde kendini gösteren sinema yıldızlarının yanı sıra az da olsa kullanılan 
erkeksi kadın imgesi üzerine değerlendirme yapılarak dönemin en ünlü kostüm tasarımcısı Travis Banton ve tasarımlarını giyen aktrislerin giysileri ile dönemin modası tartışılacaktır. Çalışmada nitel araştırma yöntemi kullanıımıştır.

\section{Hollywood'da Kostüm Tasarımının Ortaya Çıkışı}

Filmlerde kullanılan kostümler her zaman için film öyküsünün anlatımında önemli bir rol üstlenmişlerdir. Geçtiğimiz yüzyıldan günümüze filmler için kostüm hazırlanması öneminden bir şey kaybetmemiş, ancak üretim şekli oldukça değişmiştir. Amerika'da film yapımı 1890'ların ortasında New York'ta başlamış ve ilk film stüdyoları kapılarını 1896 yıında açmıştır (Landis, 2012, s. 13). Bu dönemde filmler için özel bir kostüm tasarımından bahsetmek neredeyse imkansızdır. Filmlerde kullanılan kostümlerin seçimi gelişigüzel yapılmış, filmlerde rol alan sanatçılar için özel kostümler tasarlanmamış, sanatçılar filmlerde kullanacakları giysileri kendi dolaplarından seçmişlerdir. Tarihi filmlerde ise Broadway tiyatrolarının kostüm depolarından giysiler kiralanmıştır. Gardıropları zengin olan aktrisler filmlerde daha çok ve daha uzun süreli rol almışlardır. Bu nedenle 1900-1910 yıllarında filmlerde kullanılan kostümlerin, film bütçesinde önemli bir yere sahip olmadığı görülmektedir. Örneğin Pocahontas: A Child of the Forest (Edwin S. Porter, 1908) filminde Amerikan yerlilerini, yüzlerine kahverengi boya sürülmüş beyaz aktörler canlandırmış, aktörlerin başlarına tavuk tüyleri takılmıştır (Landis, 2012, s. 13). 1905-1915 yılları arasında film yapımcılarının modaya ilgi duymadığını belirten Michelle Tolini Finamore, o dönemde sanatçıların rol aldıkları filmlerde kendi giysilerini kullandıklarını belirterek film yapımcılarının modaya ilgi duymadığından bahsetmektedir (Finamore, 2013, s. 3).

1907 yllında Amerikan film endüstrisi California Hollywood'da film çekmeye başlamış ve on yıl kadar kısa bir süre içinde Hollywood'un adı film endüstrisi ile birlikte anılmaya başlanmıştır. Film yapımcılarının Hollywood'U tercih etmelerinin en önemli nedenleri arasında Los Angeles'ın güneşli havası, yıl boyunca film çekimine elverişli olması, dağ, göl, deniz kıyısı, orman, vadi, ada ve ova gibi birbirinden farklı doğal setlere sahip olması sayılabilir (Landis, 2012, s. 14).

Hollywood film yapımcıları New York' taki uygulamayı burada da sürdürerek filmlerde, sanatçıların kişisel giysilerinin kostüm olarak kullanılması geleneğini devam ettirmişlerdir. 1910'lu yıllarda yapımcı Adolph Zukor filmlerde kreatif sanatçı olarak film kostüm tasarımcısının gerekliliğini, yönetmen D. W. Griffith ise filmlere özel kostüm tasarlanmasının önemini Amerikalılarla göstermeye çalışmıştır. İlerleyen yıllarda 
Broadway tiyatrolarının kostüm tasarımcıları Hollywood' a transfer olmuşlardır (Landis, 2012, s. 13-14).

Adolph Zukor'un yapımcılığını Üstlendiği The Loves of Queen Elizabeth (Henri Desfontaines ve Lovis Mercanton, 1912) filminde başrol oyuncusu ünlü tiyatro sanatçısı Sarah Bernhardt dönemin en tanınmış Fransız couture tasarımcısı Paul Poiret tarafından tasarlanmış kostümleri giymiştir. Sessiz film döneminin başyapıtlarından sayilan Intolerance: Love's Struggles Through the Ages (D. W. Griffith, 1916) filmi, başrol oyuncuları ve figüranları için kostümlerin özel olarak tasarlandığı ilk Hollywood filmi olarak tarihe geçmiştir (Landis, 2012, s. 14).

D. W. Griffith'in yönetmenliğini üstlendiği Birth of a Nation (1915) filminde ise oyuncu Lillian Gish'in (Görsel 1) annesi filmin kostümlerini tasarlayarak evde dikmiştir (Berg ve Engelmeier, 1990, s. 18).

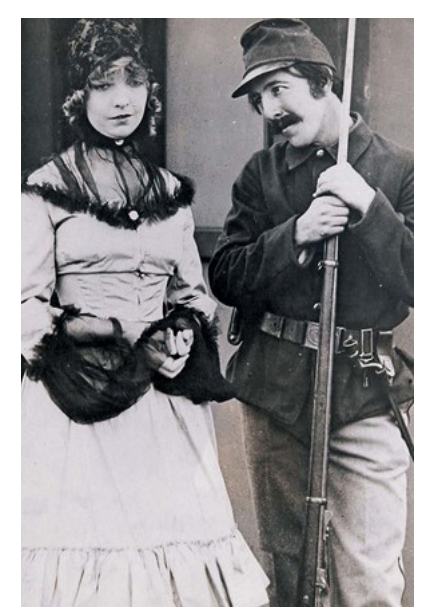

Görsel 1. Birth of a Nation (D. W. Griffith 1915) filminde oyuncu Lillian Gish (Lehr, D. ve Pfeiffer, L., 2020).

1920'lerden itibaren filmlerde kullanılan kostümlerin tasarlanması ve dikilmesi için profesyonel tasarımcılar ve terzilerle daha çok çalışılmaya başlanmıştır. Oyuncu kadrosunun giysi ve aksesuarları ile ilgilenecek profesyoneller ile anlaşma yapan yapımcı sayısı bu yıllarda giderek artmıştır. 1920'lerin sonuna gelindiğinde belli başlı film şirketlerinin hepsinde tam zamanlı çalışan, alanda kendini kanıtlamış, kostüm ve şapka tasarımcıları ile terziler görev almıştır. Filmlerde aktris ve aktörlerin giydiklerinin halk tarafından önemsenmesi, film kritiklerinin bu konuda yazmaya başlaması, uzun yıllar göz ardı edilen kostüm tasarımı alanında farkındalık yaratarak film endüstrisinde yeni bir başlangıca imza atılmasına yol açmıştır (Berg ve Engelmeier, 1990, s. 18).

Uhlirova, 1910'lu ve 1920'li yıllar boyunca sinema tekniklerinde değişen kamera açıları sebebiyle daha detaylı planların kullanıldığını belirterek, bu yıllarda 
ortaya çıkan filmlerin, moda ve sinema arasında mükemmel bir bağ kurduğuna dikkat çekmiştir. Ayrıca sinema ve moda arasındaki bu bağ, kadın izleyicilere yönelik ticari unsurların da ortaya çıkmasına neden olmuştur. 1920'li ve 1930'lu yıllarda sesli filmlerin çekilmeye başlanması modayı daha da fazla etkilemiştir (Uhlirova, $2013 \mathrm{~s}$. 140,143).

Dünya üzerinde milyonlarca kişinin hoşça vakit geçirmesine katkı sağlayan yapımlarda kostüm tasarımının önemi yadsınmazken bu alanda ilk Oscar ödülü ancak 1948 yılında verilmiştir. Filmlerde kullanılan kostüm ve aksesuarların moda olması Hollywood'u bir moda merkezine dönüştürmüş ve Hollywood uzun yıllar bu özelliğini korumuştur (Berg ve Engelmeier, 1990, s. 18).

\section{0'lu Yıllarda Kadın Modası}

1929 Ekim ayında Wall Street'in iflas etmesi, Kükreyen Yirmilerin (Roaring Twenties) aniden sona ermesi ile sonuçlanmıştır. Bu durum ekonomik anlamda Batı dünyasını etkilemiş, moda endüstrisi ve uluslararası ticaret de bu durumdan payını almıştır. Ekonomik bunalıma rağmen Empire State Binası, Chrysler Binası ve Rockefeller Plaza'nın inşasının tamamlanması New York'U modernist mimarinin merkezi yapmıştır. Hollywood filmlerinin çarpıcı ve egzotik mekanları, sürrealist hayal ürünü sahneleri, insanları gündelik yaşamın dertlerinden uzaklaştırmıştır. King Kong (Merian C. Cooper, 1933) filminin final sekansında Empire State Binası üzerinde, dev gorilin kocaman elinin içinde, şık lame bir gece elbisesi giymiş aktris Fay Wray' I tutması tüm bu farklı kültürel akımların (zor zamanlar, modanın büyüleyiciliği, sürrealizm ve art deco) birleşimini göstermesi açısından önemlidir (Cole ve Deihl, 2015, s. 161).

Dünyanın birçok ülkesinde 1930'lu yıllar ekonomik sıkıntılar ve büyük oranda işsizlik ile tanımlanırken sürrealizm, dekoratif sanatlarda ve modada etkili olmaya devam etmiştir. Giorgio Chirico ve Pierre Roy dönemin önde gelen sanatçılarından olup ilüstrasyonları moda dergilerini süslemiştir. Büyülü gerçekçilik akımının Amerikalı temsilcileri Paul Cadmus ve Ivan Albright hayali manzaralar ve portreler resmetmişler, Tamara de Lempicka ise resimlerinde büyülü gerçekçiliği art deco anlayışı ile birleştirerek şık giysiler içinde zarif kadınlar çizmiştir (Cole ve Deihl, 2015, s. 162).

Bu yıllarda daha feminen ve sofistike bir tarza doğru geçiş olduğu ve dönemin moda akımlarını dört ana kategoride incelemenin mümkün olduğu söylenebilir. Bunlar militer, romantik, Antik Yunan ve Hollywood etkisidir. Giysilerin etek ve kol boyları uzamış, bel hattı normal pozisyonuna gelmiştir. Dar elbiseler, omuz hatlarında 
ve kalça kısmında daha da genişleyen formlarda görülmeye başlamış, etek boyları uzadığı için tasarımcılar uzun boylu modeller tercih etmiştir (Laver, 2002, s. 243).

Dünyada giysi modası, tüm sınıfara yayılmaya başlamış, ekonomik bunalım farklı sınıfara mensup kişilerin giyim tarzını birbirine yakınlaştırarak kadının değişen toplumsal rollerine uygun olarak şekillenmiştir. Bluz ve etek takımlar kadınların, iş yaşamında tercih ettiği giysiler olmuştur. 1920'lerin vazgeçilmezi çan şapkanın modasının geçmesi ile kadınlar yeniden saçlarını uzatmaya başlamıştır. Moda olan sırt dekoltesi günlük giysilerde sırtta yırtmaç şeklinde kullanılırken, gece kıyafetlerinde bele kadar uzatılmıştır. Kadın giyiminde Grek heykellerini andıran silüetler yakalanmaya çalışılmıştır. (Laver, 2002, s. 243-248).

1930'larda yaşanan ekonomik sıkıntılar nedeniyle giysilerde süslemenin azaldığı sadeliğin ön planda olduğu görülür. Giysileri görsel olarak cazip hale getirebilmek için asimetrik parçalar, pliler, büyük fiyonklar, pelerinler, şallar, atkılar, fırfırlı yakalar ve fırfırlı bluzlar tercih edilmiştir. Bu dönemde rejenere selülozik liflerden viskoz ve asetattan üretilmiş, parlak kumaşlar ipek yerine kullanılmaya başlanmıştır. 1930'ların sonlarına doğru giysilerde simetri bir kez daha yaygınlaşmıştır. Giysi kollarında çeşitlilik göze çarparken Viktorya dönemine özgü gigot kol yeniden moda olmuş, omuzdan itibaren açılan kol yırtmacı kadınlara daha feminen bir görünüm kazandırmıştır. Vatkalar ile genişleyen omuzlar daha geniş etekler ile dengelenmiştir (Cole ve Deihl, 2015, s. 166).

Verev kesim giysiler 1930'lu yıllarda moda olmayı sürdürmüştür. 1930'ların başında uzun etekler modayken, 1939 yılında etek boyları kısalarak dizalıına gelmiştir. Bu dönemde kadınlar için bol pantolonlar da tasarlanmıs, aktris Katharine Hepburn ve Marlene Dietrich bu modanın öncüleri olmuştur (Cole ve Deihl, 2015, s. 166).

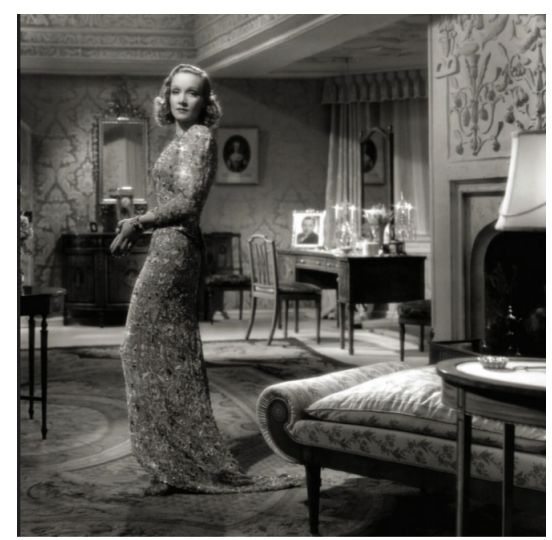

Görsel 2. Marlene Dietrich, Angel (Ernst Lubitsch, 1937) filmindeki kostümüyle (Jorgensen J. ve Scoggins D.L., 2015, s. 163). 
Günlük giysilerde sadelik ön plandayken gece kıyafetlerinde tüm kadınlar için Hollywood kostüm tasarımcılarının yıldız oyuncular için tasarladığı kostümler ilham kaynağı olmuştur. Boncuk işlemeler, kürkler, püsküller ve aplikeler gece kıyafetlerinin en dikkat çekici süsleme unsurlarıdır (Görsel 2). Bu kıyafetlerde çoğunlukla mat saten, şarmöz, lame ve sire saten kumaşlar kullanılmıştır. Dantel yine gece kıyafetlerinin vazgeçilmez kumaşlarından biridir. Gece kıyafetlerinde etek boyları ya yere kadar uzatımış ya da ayağın hemen üzerinde bırakılmıştır. 1930'ların sonuna gelindiğinde ise gece kıyafetlerinde etek boyu biraz daha kısalarak midi etekler tercih edilmiştir (Cole ve Deihl, 2015, s. 166).

\section{0'lu Yıllarda Hollywood Yıldızlarının Modaya Ełkisi ve Travis Banton}

Filmler her zaman moda iletişimi ve moda bilgisinin yayılımında önemli bir araç olmuştur. Bu iki alan başlangıçta birbirinden ayrı gibi görünse de sonrasında tamamen kendi doğalarına uygun olarak birbirlerine eşlik etmişlerdir. Bu durumun günümüzde de devam ettiği söylenebilir.

1930'lu yllarda film kostümleri sinema endüstrisi açısından son derece değerli, özel bir yere sahip olmuştur. Bu süreçte filmler ve film yıldızları kadar dönemin modasını tanımlayan aktörlerden biri de kostüm tasarımcılarıdır. Kostüm tasarımcısı, filmdeki her bir karakterin nasıl bir imaja sahip olacağına karar vererek tasarımlarını gerçekleştirir. Bir yapımın başarısı bir ölçüde de kostüm tasarımcısının başarısına bağlıdır. Kısaca tasarımcının sorumluluğu büyüktür, o sadece kreatif bir sanatçı değil, aynı zamanda tarihçi, araştırmacı ve usta bir terzidir (Hepburn, 1990, s .9).

\section{Travis Banton'ın New York Yılları}

Hollywood sinema tarihinde kostüm tasarımı kavramını yerleştiren ve moda tarihinde oldukça önemli bir yere sahip olan kostüm tasarımcılarından biri hiç kuşkusuz Travis Banton'dur. Travis Banton, Mae West, Carole Lombard, Claudette Colbert, Anna May Wong ve Marlene Dietrich gibi birçok Hollywood yıldızına kostüm tasarlamıştır. Ancak Marlene Dietrich, Banton'un kariyerinde her zaman için özel bir yer tutmuştur (Cole ve Deihl, 2015, s. 184).

Banton, 18 Ağustos 1894 yılında Texas Waco'da doğmuştur. Baba Rentfro, anne Margaret Jones Banton ve kız kardeşi Ruth ile birlikte, Travis iki yaşındayken New York'a taşınmışlardır (Jorgensen ve Scoggins, 2015, s. 154). Travis Banton, çocukluğunu annesi ile birlikte gittiği New York tiyatrolarının matinelerinde geçirmiştir. 
Yaşamının büyük bir bölümününde muhasebecilik yapan, babası Rentfo, oğlunun da iş hayatına atılmasını istemiştir. Bu nedenle Travis Banton 16 yaşında Colombia Üniversitesi'nde işletme alanında eğitim almaya başlamıştır. Ancak çocukluğundan itibaren sanata karşı büyük bir yeteneği olan Banton, ailesinin de onayını alarak eğitimine sanat alanında devam etmiştir. Eğitimi sırasında nü model çizimlerine elbise, mücevher ve diğer moda aksesuarları eklemesi öğretmenlerinin dikkatini çekmiştir. Öğretmenleri onu, moda tasarımı alanında dersler alması için cesaretlendirmişlerdir. Sonraki yıllarda kendisi ile yapılan bir röportajda Banton, ilk başta moda alanında kariyer yapma fikrinin kendisini dehşete düşürdüğünü söyleyerek moda tasarımını daha kadınsı bir meslek olarak gördüğünü ifade etmiştir. Bu açıklama basın için yapılmış olup asında annesi oğlunu her zaman için moda tasarımcısı olması yönünde teşvik etmiştir. Anne, Margaret Jones Banton, bir moda tasarımcısı olarak hayatını kazanmanın bir ressam ya da heykeltraş olarak hayatını kazanmaktan çok daha kolay olduğunu oğluna ifade etmiştir (Jorgensen ve Scoggins, 2015, s. 157).

1916 ylında Banton henüz bir öğrenci iken, şöhretinin zirvesinde olan Norma Talmadge ile tanışmıştır. Aktris, Poppy (Edward José, 1917) filminin çekimleri için New York'tadır ve Banton'ın tasarımları ile ilgilendiğini belirtmiştir. Profesyonel anlamda deneyimi olmayan Banton, çizimlerini çekingen bir tavırla Talmadge'ye göstermiş ve aktris filminde giymek üzere birini seçmiştir. Talmadge giysinin provalarında Banton'ın bulunmasını istemiştir. Sonraki yıllarda Banton o günü şu şekilde anlatmıştır. "Deneyimsiz olduğum için provalar çok uzun sürmüştü, ama Talmadge bana karşı büyük bir sabır gösterdi." Poppy' nin çekimlerinin bitmesinin ardından Amerika Birleşik Devletleri

I. Dünya Savaşı'na girmiş, Banton denizci olarak bir denizaltıda görev almıştır. Savaştan sonra New York'a dönmüş ve New York School of Fine and Applied Arts'daki eğitimini tamamlamıştır. Ardından Vogue dergisine bazı çizimlerini satmış ve Madame Frances Modaevi'nde tam zamanlı olarak işe başlamıştır. Modaevi'nin müşterileri arasında New York sosyetesi ve Broadway yıldızları yer almaktadır (Jorgensen ve Scoggins, 2015, s. 158).

Ancak moda dünyasının Banton'un tanıması 1920 yılına rastlamaktadır. Banton 1920 yılında Madame Francis Modaevi'nde tasarladığı bir gelinlik, dönemin önemli moda dergilerinden birinde basılmıştır. Ertesi gün Modaevi'ne gelen bir müşteri gelinliği prova odasında denemek istediğini söylediğinde modaevi bir anda hareketlenmiştir (Cole ve Deihl, 2015, s.153). Gelinliği almaya gelen kişi 
Douglas Fairbanks ile birkaç gün içinde gizlice evlenecek olan ünlü film yıldızı Mary Pickford'dan başkası değildir (Berg ve Engelmeier, 1990, s. 22). Pickford'un, Banton'un tasarımını yaptığı gelinliği giymesi Banton'un moda tasarımcısı olarak ünlenmesine yol açmıştır. Lady Duff-Gordon ile bir süre çalışan Banton daha sonra kendi modaevini açmıştır. Bu dönemde The Ziegfeld Follies (Julian Mitchell, 1924), Little Miss Bluebeard (William H. Gilmore, 1924) ve My Girl (Walter Brooks, 1924) gibi tiyatro oyunlarının kostüm tasarımlarını gerçekleştirmiştir (Jorgensen ve Scoggins, 2015, s. 158).

\section{Travis Banton'ın Hollywood Yılları}

Paramount şirketi ile çalışan film yapımcısı Walter Wanger 1924 yılının soğuk bir kış gününde Banton'ı telefon ile arayarak The Dressmaker from Paris (Paul Bern, 1925) filminde kostüm tasarımcısı olarak çalışıp çalışamayacağını sormuştur. Wanger'in eşi, aktris Justine Johnstone, Banton'ın müşterisidir. New York'un kışlarından sıkılan Banton alacağı ücreti bile sormadan teklifi kabul etmiştir. The Dressmaker from Paris filminin final sahnesi görkemli bir defile ile son bulmaktadır. Banton, filmlerde kostüm tasarımcısı olarak kariyer yapmak için bu filmden daha iyi bir fırsat hayal bile etmemiştir. The Dressmaker from Paris filminden sonra Paramount, Banton'a haftada 150\$ kazanabileceği bir sözleşme teklif etmiş, Howard Greer Paramount'un baş tasarımcısı, Banton ise ikinci tasarımcı olarak beraber çalışmaya başlamışlardır (Jorgensen ve Scoggins, 2015, s. 160).

Travis Banton 1925 yılında aktris Clara Bow ile tanışmış ve onun ışığından çok etkilenmiştir. It (Clarence G. Badger ve Josef von Sternberg, 1927) filmi için aktriste tasarladığı kostümler (Görsel3) dönemin genç kadın modasına damgasını vurmuştur. Banton, Bow'U sürekli olarak abartılı aksesuarlar kullanmaması konusunda uyarmıştır. Bir prova sırasında Bow'a, "Unutma, bu sade beyaz krep elbise ile abartılı küpeler takmamalısın" dediği bilinir. Ancak Bow yine de kulağından omuzlarına kadar inen bir küpe takarak, "bak seni mutlu etmek için iki değil, tek küpe taktım" demiştir (Jorgensen ve Scoggins, 2015, s. 160).

1927 yılında Banton kendini yenilikçi bir tasarımcı olarak kanıtlamıştır. O dönemde en çok tasarladığı, vücudu saran gece kıyafetleri ile tanınmış, bu giysiler tamamen boncuk, pul ve payetlerle işlenmiş ya da kürk ile süslenmiştir. Yıldız oyuncular baş tasarımcı Howard Greer'in yerine Banton'un giysilerini tasarlamasını istemiştir. Kendi yeteneğine kostüm tasarımcısı olarak hiçbir zaman tam olarak güvenmeyen 
Greer istifa etmiş ve Banton Paramount'un baş tasarımcısı olmuştur (Jorgensen ve Scoggins, 2015, s. 161).

Banton, bir karakterin kostümleri tasarlarken bunu önce zihninde canlandırıp her kostüm için tek bir skeç çizdiğini ve her bir aktris için belirgin ve diğerlerinden ayırt edici bir kimlik oluşturduğunu ifade etmiştir. Hafızalara kazınan sayısız kostüm tasarlayan Banton, filmlerde karakterin ön planda olması gerektiğine inandığını dile getirmiştir (Landis, 2012, s. 132-134).

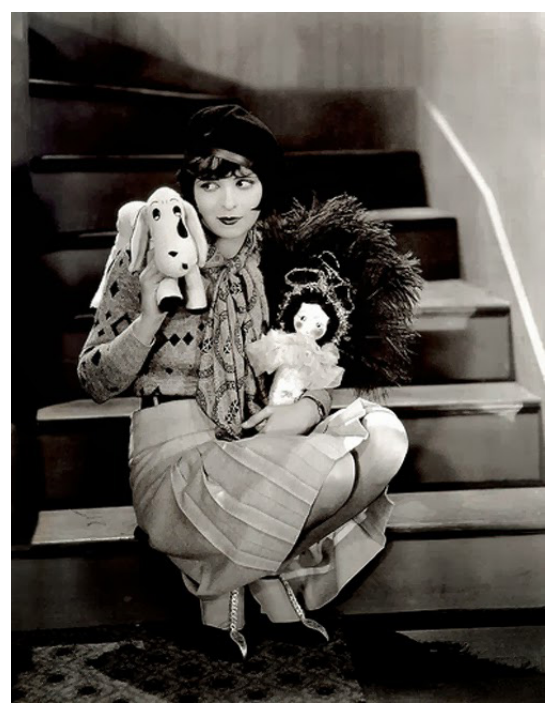

Görsel 3. Clara Bow, It (Clarence G. Badger ve Josef von Sternberg, 1927) filmindeki kostümüyle (Truhler, 2013).

Claudette Colbert, filmlerdeki kostümleri için Banton'a ihtiyaç duyduğuna inanmamıştır. Manslaughter (George Abbott, 1930) filmi için Paramount şirketi ile anlaştığında Saks Fifth Avenue' dan satın aldığı bir bagaj dolusu giysi ile sete gelmiştir. Banton'ın sözleşmesi şirket ile çalışan her sanatçının gardrobunu kontrol etme yetkisi kendisine tanımıştır. Ancak Banton bu konuda Colbert'iserbest bırakarak oynayacağı filmlerde giyeceği kostümleri istediği yerden satın almasına izin vermiştir. Bu durum The Man from Yesterday (Berthold Viertel, 1932) filminin çekimlerinde sona ermiştir. Colbert film çekimleri öncesinde giysi alışverişi yapmak için zaman bulamamıştır. Banton, Colbert için yaptığı çizimleri (şifon bir elbise, pelerinli bir giysi ve fiyonklu günlük bir giysi) göstermiş, ancak sanatçıdan olumsuz eleştiriler almıştır. Colbert diğer filmlerde de Banton'un seçimlerini eleştirmeye devam etmiştir (Jorgensen ve Scoggins, 2015, s. 154). Colbert'in Cleopatra (Cecil B. De Mille, 1934) filminde giydiği etkileyici elbiseleri ve filmdeki verev kesim, yeşil saten elbiseyi de (Görsel 4 ve Görsel 5), Banton tasarlamıştır (Cole ve Deihl, 2015, s. 184). 
Carol Lombard'a tasarım yapmak ise Banton'un Colbert ile yaşadığı gerilimi bir nebze olsun hafifletmiştir. Lombard, Banton'ın kendisi için yaptığı tasarımları her zaman büyük bir coşku ile karşılamıştır (Jorgensen ve Scoggins, 2015, s. 154).

Travis Banton uluslararası alanda modayı belirleyen bir kişi olarak kabul edilmiştir. Paramount şirketinin halkla ilişkiler bölümü Travis'in kostümlerini filmlerde hayranlıkla takip eden kadın izleyicilere, Travis'in stil danışmanlığı yapacağını duyurmuştur. Travis Banton ayrıca verev kesim elbiseleri ve elbiselerde beyaz renk kullanımı ile de ün salmıştır. Banton'ın Pola Negri için tasarladığı beyaz giysiye kadar Hollywood setlerinde beyaz kabul gören bir renk olmamıştır (Landis, 2012, s. 134-135).

1937 yılına gelindiğinde Travis Banton, Paramount şirketine bağlı çalışan her yıldız oyuncunun çalışmak istediği bir tasarımcı haline gelmiştir. Haftada $1250 \$$ gibi oldukça yüksek bir ücret alan Banton, kendisinin Paramount için vazgeçilmez olduğunu düşünmeye başlamıştır. Sözleşmesinin yenilenme zamanı geldiğinde yöneticisinin tavsiyelerine uyarak daha fazla bir ücret talep etmiş, Paramount ise kostüm bütçesinde bir kısıtlamaya gitmeyi planladığından bunu kabul etmeyerek Banton' a aldığı ücret kadarını teklif etmiştir. Bunu reddeden Banton, Paramount'dan ayrılmak zorunda kalmıştır (Jorgensen ve Scoggins, 2015, s. 161).

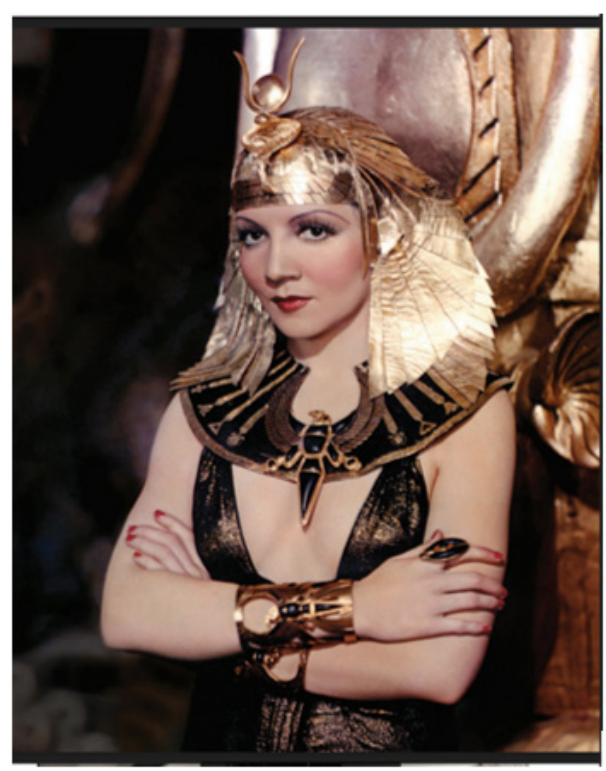

Görsel 4. Claudette Colbert, Cleopatra (Cecil B. DeMille, 1934) filmindeki kostümüyle (Jorgensen J. ve Scoggins D.L., 2015, s. 155). 


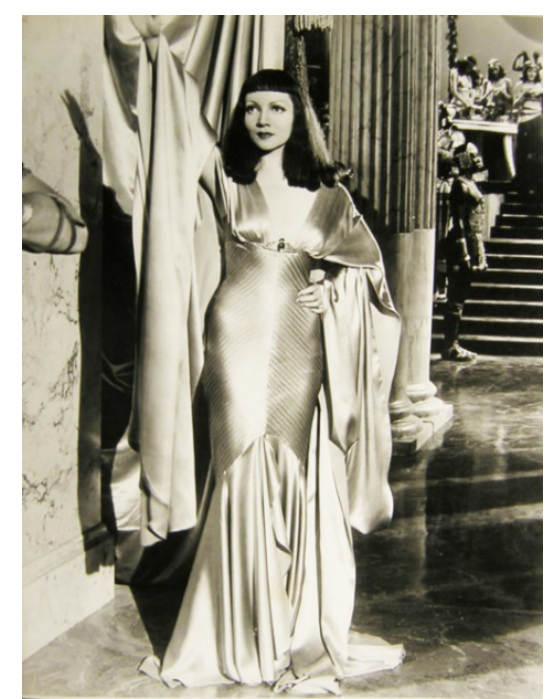

Görsel 5. Claudette Colbert, Cleopatra (Cecil B. DeMille. 1934)filmindeki verev kesim kostümüyle (Old Fashioned Way, 2014).

Banton, Paramount'da birlikte görev aldığı Howard Greer'ın modaevinde onunla birlikte çalışmaya başlamışır. i ikili, 1939 ylında Sunset Bulvarı'ndaki atölyelerinde ortak bir koleksiyon hazıllamışıı. Banton aynı zamanda tek başına yapacağı işler arasa da eski müşterilerini tekrar kazanmakta zorlanmışıı. 1938 ve 1939 yllları arasında United Artists, 1939-1941 yilları arasinda da 20th Century Fox için çalışmıştır. 1942 yılının Temmuz ayında köşe yazarı Hedda Hopper, Banton'un 20 yıl önce Columbia Üniversitesi'nde öğrenci iken tanıştığı Elizabeth "Biddy" Kleitz ile evlendiğini okurlarına duyurmuştur (Jorgensen ve Scoggins, 2015, s. 161).

Biddy, Columbia'dan mezun olduktan sonra bir yayınevinde çalışmıs, daha sonra reklamcllik alanında kariyerine devam etmiştir. İkisi de 40'lı yaşlarının ortalarında olup ilk evliliklerini yapmışıır. Eşi, Banton'ı yeniden tasarım yapıp satması konusunda cesaretlendirmiştir. Biddy'in daha önce reklamclık alanında çalışı̧̧ olması her ikisi için yeni firsatlar doğurmuştur. Banton, yeni hazır giyim koleksiyonunu tanııırken eşi onunla birlikte seyahat ederek Banton'ı desteklemiştir. Eşi ile birlikte basındaki görünürlüğü Biddy'nin 1946 yllında New York Times'ın Hollywood moda editörü olarak çalışmasına yol açmışıı. Hollywood'da düzenlenen yardım balolarında da aktif rol alan Biddy, 1948 yll Christmas balosunda Frank Sinatra, Douglas Fairbanks Jr., ve Esther Williams ile birlikte Los Angeles'ta inşa edilecek Körler Okulu için 65,000\$ tutarında yardım toplamışlardır (Jorgensen ve Scoggins, 2015, s. 164).

Banton, Down Argentine Way (Irving Cummings, 1940) filminde Betty Grable'In, Tin Pan Alley (Walter Lang, 1940) filminde Grable ve Alice Faye'in kostümlerini tasarlamak için 20th Century Fox şirketi ile anlaşmışıı. Ancak bu 
filmlerdeki kostümler, Banton'un Paramount'da alıştığı sofistike tarzdan çok uzaktır. Columbia ile sürekli bir sözleşme yapmayı kabul etmeyen Banton, şirket için dört filmin kostümlerini tasarlamıştır. Bunlardan biri modern giysi tasarımları yaptığı Cover Girl (Charles Vidor, 1944) filmidir (Jorgensen ve Scoggins, 2015, s. 164).

Hollywood partilerini artık anlamsız bulan Banton, tiyatroyu, operayı, baleyi ve New York'un dükkanlarını bile çok özlemiştir. Valentino (Lewis Allen, 1951) filminden sonra, filmler için kostüm tasarımı yapmayı bırakarak yeniden Howard Greer ile beraber çalışmaya başlamıştır. Filmler için tasarım yapmasa da Rosalind Russel'in oynadığı Auntie Mame (Morton da Costa, 1956) adlı tiyatro oyunu için sanatçıya özel kostümler tasarlamayı kabul etmiştir. Banton, Russel için 1928 ylından 1940'ların sonlarına kadar kürk ve boncuklarla bezenmiş sabahlıklar tasarlamıştır. 1950'lerin ortalarında The Dinah Shore Chevy Show'un (Bob Banner, 1956-1963) kostümleri için Marusia Toumanoff ile birlikte çalışmıştır. 1958 yıının başlarında Marusia-Travis Banton markasını kurarak couture koleksiyonlarını sunmuşlardır. Travis Banton, 2 Şubat 1958'te Los Angeles'ta yaşamını yitirmiştir (Jorgensen ve Scoggins, 2015, s. 165).

\section{Marlene Dietrich ve Travis Banton}

Travis Banton Marlene Dietrich ile 1930 yılının Haziran ayında Morocco (Josef von Sternberg, 1930) (Görsel 6) filminin setinde tanışmıştır. Filmin yönetmeni Josef von Sternberg, Dietrich'in sahnelerini gece yarısına kadar çektiği için provalar ancak gece yarısından sonraya kalmıştır. Oldukça yorgun olan Marlene Dietricht durumdan hiç şikayet etmemiş, sessizce provanın bitmesini, beklemiştir. Sabahın ilk ışıklarına kadar süren prova sırasında Dietrich'in neredeyse tek bir kelime bile konuşmaması Banton'ı oldukça rahatsı etmiştir. Banton, "Bir şey söyle. Herhangi birşey söyle. Korkunç, imkânsız, amatör de ama yeter ki bir şey söyle" diye bağırmak istemiştir. Yıllar sonra Banton, bu sessizliğin nedeninin, Dietrich'in lisan ile ilgili yaşadığı huzursuzluk ve Amerika' nın eşitlikçi toplum anlayışına duyduğu akıl karışıklığı hissinden kaynaklandığını fark etmiştir. Almanya'dan Hollywood'a yeni gelen bir aktris olan Dietrich de filmin kostüm tasarımcısına ve ekibine ne şekilde davranacağını bilememiştir (Jorgensen ve Scoggins, 2015, s. 154).

Hollywood köşe yazarlarından Hedda Hopper, Dietrich'in Travis Banton ile tanısmadan önce, bir yıldızdan çok tipik bir Alman ev kadınına benzediğini belirterek, 


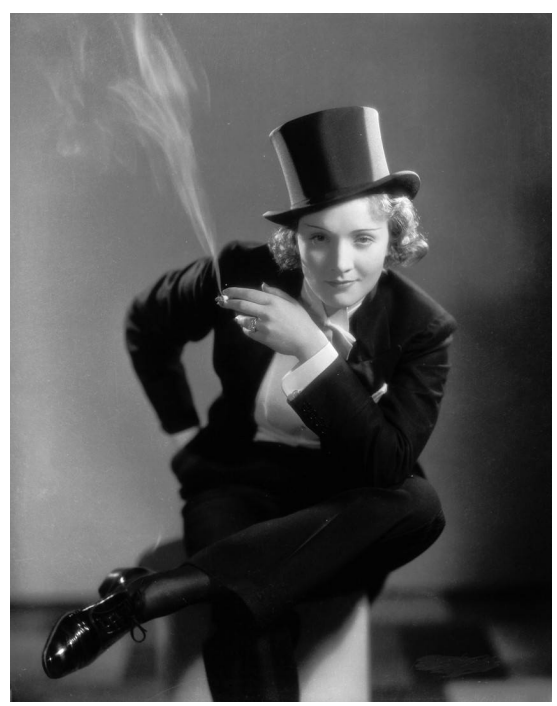

Görsel 6. Marlene Dietrich, Morocco (Josef von Sternberg, 1930) filmindeki maskülen kostümüyle (Internet Archive, 2021).

Banton'un yönetmen Joseph von Sternberg ile bıkıp usanmadan Dietrich'in toplum önündeki imajı üzerine çalıştıklarından bahsetmiştir. Hopper, "Onlar öyle bir ekip oluşturmuşlardı ki tek kabul edilebilir çıktı mükemmelliyetti"demiştir (Landis, 2012, s. 132-133). Marlene Dietrich'in kızı Maria Riva, o günleri şöyle anlatmıştır: "Annem ve Banton gece gündüz, bazen günde 12 saatten fazla çalışırlardı. Annem hiçbir zaman yorulmaz, Banton ile filmin kostümleri üzerinde çalışıllarken, dinlenme, yemek yeme gibi normal intiyaçlar için bile ara vermezlerdi." (Landis, 2012, s. 134).

Banton bir keresinde "Marlene için giysi yapmayı seviyorum ama bazen onun egzotik kişiliği beni zorluyor" demiştir. Dietrich'in tüylere olan tutkusu nedeniyle Banton Shangai Express (Josef von Sternberg, 1932) filmi için siyah, parlak tüylü, ikonik vamp bir giysi (Görsel 7) tasarlamıştır. Dietrich'in omuzlarından itibaren boynunu tamamen kaplayan tüylü giysisi bir süre sonra Amerikalı kadınlar arasında da moda olmuştur. Günlük giyimde kullanılmayacağı düşünülen tüyler, birçok kadın tarafından tercih edilmiş, Banton, "Amerikalı kadınların üzerinde gördüğünüz cennet kuşlarının sayısına inanamazsınız. Bu tüyleri giysilerinde her yere yerleştirdiler" diyerek tüylerin nasıl moda olduğunu aktarmıştır (Jorgensen ve Scoggins, 2015, s. 154).

Banton'un Blonde Venus (Josef von Sternberg, 1932) filminde Dietrich için tasarladığı erkeksi, beyaz takım elbise (Görsel 8) o dönemde neredeyse ufak çaplı bir skandal yaratmıştır. Dietrich gündelik yaşamında da zaman zaman pantolon giymeyi tercih etmiştir (Cole ve Deihl, 2015, s. 184). Geniş paçalı pantolonlar o dönemde resmi olmayan gece toplantılarında giviliyor olsa da bu pantolonlar 
Marlene Dietrich tarafından giyilen erkeksi takım elbiselerden daha farklı bir konumda yer almıştır. $\bigcirc$ yıllarda takım elbise, cinsiyetleri belirsizleştiren bir giysi olarak görülmesine rağmen Marlene Dietrich erkeksi aksesuar kullanımını da içeren kişisel tarzı ile dikkatleri çekmiştir (Fogg, 2011, s.266). Marnie Fogg' a göre "Dietrich, erkek kılığının renkleri içinde kendini güçlü bir şekilde ortaya koymaya devam etti ve kuşku götürmez kadınsı özelliklerini mesafeli tarzıyla sertleştirerek, itaatkar sarışın stereotipinin antitezi oldu" (Fogg, 201, s. 267).

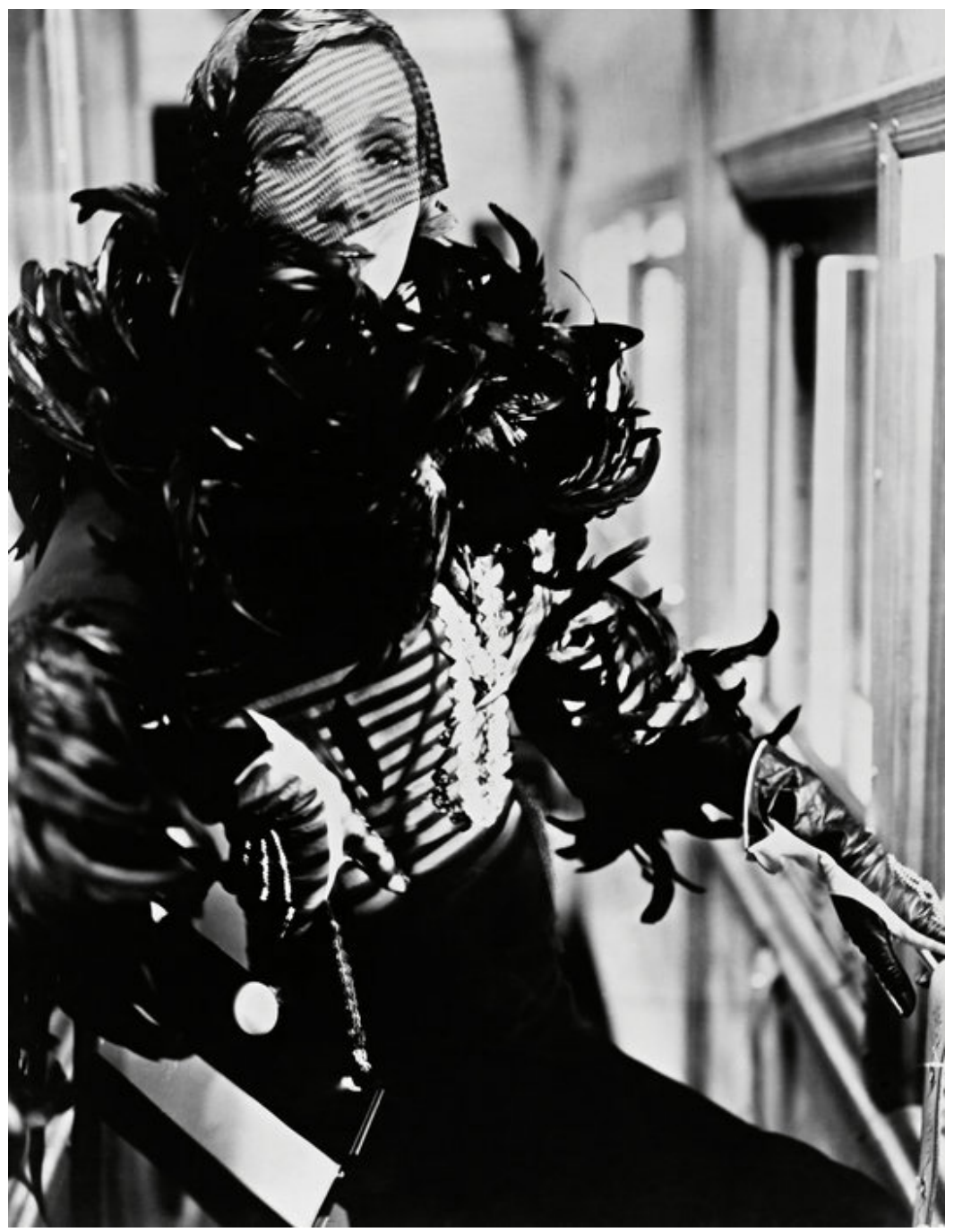

Görsel 7. Marlene Dietrich, Shanghai Express (Josef von Sternberg, 1932) filmindeki kostümüyle (Banton, 2001, s. 32). 


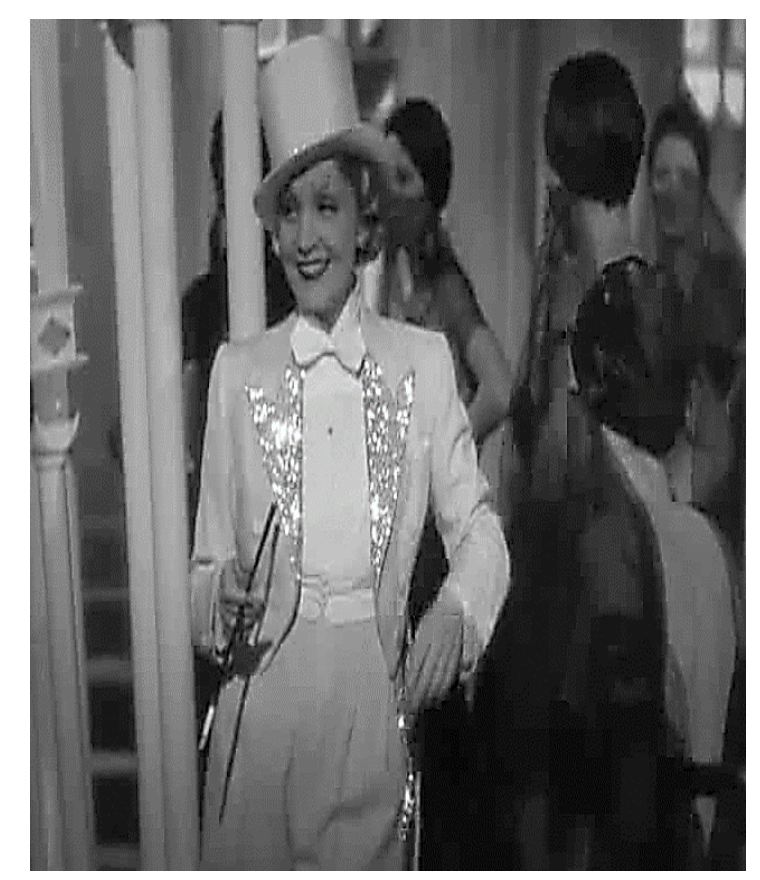

Görsel 8. Marlene Dietrich, Blonde Venus (Josef von Sternberg, 1932) filminde beyaz takım elbisesiyle (Arabesques, 2010).

Dietrich'in Angel (Ernst Lubitsch, 1937) filminde (Görsel 9) giydiği vücuduna tamamen oturan, üzeri boncuk işlemeli ve kürkile çevrelenmiş bir etolün tamamladığı gece kıyafeti, Banton'ın Dietrich için tasarladığı en pahalı kostüm olmuştur (Jorgensen ve Scoggins, 2015, s. 161).

Banton, Marlene Dietrich için Morocco (Josef von Sternberg, 1930) filminde Mademoisele Amy Jolly, Dishonored (Josef von Sternberg, 1931) filminde Marie Kolverer, Blonde Venus (Josef von Sternberg, 1932) filminde Helen Faraday nam-I diğer Helen Jones, Shanghai Express (Josef von Sternberg, 1932) filminde Shanghai Lily, The Scarlet Empress -Her Regiment of Lovers (Josef von Sternberg, 1934) filminde Princess Sophia Frederica/Catherine II, The Devil is a Woman (Josef von Sternberg, 1935) filminde Concha Perez, Desire (Frank Borzage, 1936) filminde Madeleine de Beaupre ve Angel (Ernst Lubitsch, 1937) filminde Lady Maria Barker karakterleri için kostüm tasarlamıştır ("Marlene Dietrich Filmography", 2021, para. 2). 


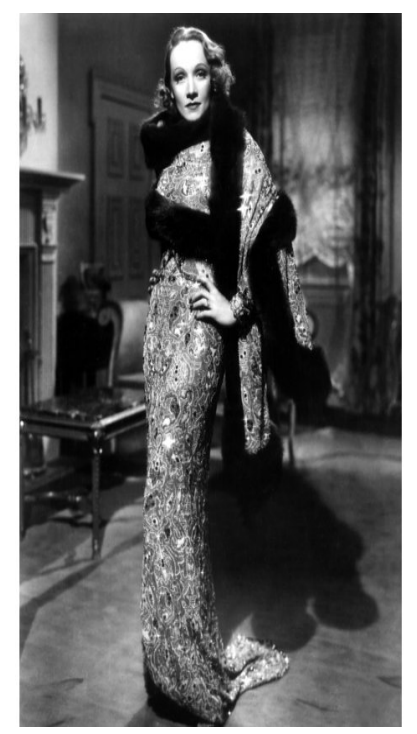

Görsel 9. Marlene Dietrich'in Angel (Ernst Lubitsch, 1937) filminde giydiği gece kıyafeti (Fine Art America, 2011).

\section{SONUÇ}

Amerika'da 1890'ların ortasında New York'ta başlayan film yapımı, 1910'lardan itibaren Hollywood'a kaymıştır. Ancak bu dönemde filmler için özel bir kostüm tasarımından bahsetmek neredeyse imkansızdır. Hollywood, 1930'lu ylllarda moda üzerinde oldukça etkin olmuş ve neredeyse bir moda merkezine dönüşmüştür. 1929 yllı sonrası Büyük Ekonomik Bunalım döneminde sinemaya gitmek, filmlerdeki albenili kostümleri seyretmek, insanları bir nebzede olsa gerçek yaşamın zorluklarından uzaklaştırarak onların hoşça vakit geçirmelerini sağlamıştır. 1930'larda New York hazır giyim tasarımcıları, halkın değerlerini yansıtan yeni bir tarz geliştirmişlerdir. Bu yeni tarz, farklı kıyafet parçalarının karıştıılıp farklı durumlara uygun hale getirilmesinden ibarettir. Adrian, Walter Plunket ve Travis Banton gibi Hollywood'lu tasarımcılar Jean Harlow, Joan Crawford ve Marlene Dietrich gibi yıldızlar için göz alıcı kıyafetler tasarlamışlardır. Sonuç olarak film yıldızlarını başarı ile giydiren bu tasarımcılar Hollywood tarzını oluşturarak 1930'lı yılların modasına damgalarını vurmuşlardır (Fischel vd., 2010, s. 270).

Gilbert Adrian, Edith Head ve Walter Plunkett gibi isimleri arasında Travis Banton, Hollywood sinemasının moda endüstrisi üzerinde büyük bir etkiye sahip olmasını sağlayan en önemli isimlerinden biri olmuştur (Fischel vd., 2012, s. 306). Özellikle kadın seyirciler sinema perdesin de izlediği karakterin giysilerinden etkilenerek ona benzer bir imaja sahip olmak istemiştir. Film yıldızının giydiği bir giysi, kullandığı 
bir aksesuar, saç modeli veya makyajı bir anda moda haline gelerek milyonlarca kişi tarafından kullanılmaya başlamıştır. Sinema ve film yıldızlarını giydiren kostüm ve moda tasarımcıları olmadan modanın bu kadar hızla yayılamayacağı bir gerçektir (Engelmeier ve Engelmeier, 1990, s. 7). 1930'lu yllarda tüm bu feminen görünümler içinde bazı ikonik erkeksi stiller de göze çarpmaktadır. Bu tasarımlar moda tarihinin ikonik görüntüleri arasındaki yerlerini almıştır. Hollywood'un 1920'lerden itibaren modayı etkilemeye başladığı, bu etkinin 1930'lu yıllarda önemlikostüm tasarımcılarının etkisi ile daha da belirginleştiği görülür. Bu etkinin günümüzde de devam ettiğini söylemek mümkündür.

\section{KAYNAKÇA}

Abbott, G. (Yönetmen). (1930). Manslaughter [Film]. ABD: Paramount.

Allen, L. (Yönetmen). (1951). Valentino [Film]. ABD: Columbia.

Arabesques. (2010, 17 Ağustos). Marlene Dietrich: Blonde Venus. https:// circeo59.wordpress.com/2010/08/17/marlene-dietrich-blonde-venus-josef-vonsternberg-1932/, Erişim tarihi: 31 Ocak 2021

Badger, C. G. ve Sternberg von J. (Yönetmen). (1927) It [Film]. ABD: Paramount.

Berg, A. ve Engelmeier R. (1990). Design or No Design: Costume Designers and Couturiers in the Great Days of Hollywood. R. Engelmeier ve P. W. Engelmeier (Ed.), Fashion in Film (s. 18-21). Münih: Prestel.

Bern, P. (Yönetmen). (1925) The Dressmaker from Paris [Film]. ABD: Paramount.

Borzage, F. (Yönetmen). (1936). Desire [Film]. ABD: Paramount.

Brooks, W. (Yönetmen). (1924). My Girl [Müzikal oyun]. ABD: Vanderbilt Theatre.

Cole, D. J. ve Deihl, N. (2015). The History of Modern Fashion: From 1850. Londra: Laurence King.

Cooper, C. M. (Yönetmen). (1933). King Kong [Film]. ABD: Universal.

Costa da, M. (Yönetmen). (1956). Auntie Mame [Tiyatro oyunu]. ABD: Broadhurst Theatre. 
Cummings, I. (Yönetmen). (1940). Down Argentine Way [Film]. ABD: 20th Century Fox.

De Mille, B. C. (Yönetmen). (1934). Cleopatra [Film]. ABD: Paramount.

Engelmeier, R. ve Engelmeier, P. W. (1990). A Touch of Mink. R. Engelmeier ve P. W. Engelmeier (Ed.), Fashion in Film (s. 7-8). Münih: Prestel.

Fine Art America. (2011, 2 Aralık). Angel: Marlene Dietrich. https:// fineartamerica.com/featured/angel-marlene-dietrich-costume-still-everett.html, Erişim tarihi: 12 Marł 2021

Finemore, M. T., (2013). Hollywood Before Glamour: Fashion in American Silent Film. Hampshire: Palgrave Macmillan.

Fischel, A., Baggaley, A. O'Hara, S., Sturgeon, A., Gersh, C. ve Khurana, A. (Ed.) (2012). Moda: Geçmişten Günümüze Giyim Kumaş ve Stil Rehberi (Çev. D. Özen). İstanbul: Kaknüs.

Fogg, M. (2013). Fashion The Whole Story. Londra: Thames\&Hudson.

Gilmore, W. H. (Yönetmen). (1924). Little Miss Bluebeard [Tiyatro oyunu]. ABD: Lyceum Theatre.

Griffith, D. W. (Yönetmen). (1915). Birth of a Nation [Film]. ABD: Epoch.

Griffith, D. W. (Yönetmen). (1916). Intolerance: Love's Struggles Through the Ages [Film]. ABD: Triangle.

Hepburn, A. (1990). The Costumes Make the Actors. R. Engelmeier ve P. W. Engelmeier (Ed.), Fashion in Film (s. 9-11). Münih: Prestel.

Internet Archive. (2021, 30 Ocak). Marlene Dietrich. https://archive.org/ details/3-smoking-amy-marlene-dietrich-making-her-hollywood-film-debut-as-thetuxedo-cla, Erişim tarihi: 31 Ocak 2021

Jorgensen J. ve Scoggins D. L. (2015). Creating the Illusion: A Fashionable History of Hollywood Costume Designers. Filedelfiya: Running.

José, E. (Yönetmen). (1917). Poppy [Film]. ABD: Selznick.

Landis D. N. (2012). Setting the Scene A Short History of Hollywood Costume Design 1912-2012. D. N. Landis (Ed.), Hollywood Costume (s. 13-45). Londra: V\&A Museum. 
Lang, W. (Yönetmen). (1940). Tin Pan Alley [Film]. ABD: 20th Century Fox.

Laver, J. (2002). Costume and Fashion: A Concise History. Londra: Thames and Hudson.

Lehr, D. ve Pfeiffer, L. (2020, 23, Mart). The Birth of a Nation. Encyclopedia Britannica. https://www.britannica.com/topic/The-Birth-of-a-Nation, Erişim tarihi: 31 Ocak 2021

Lubitsch, E. (Yönetmen). (1937). Angel [Film]. ABD: Paramount.

Mercanton, L. ve Desfontaines, H. (Yönetmen). (1912). The Loves of Queen Elizabeth [Film]. Fransa: L'Histrionic Film.

Mitchell, J. (Yönetmen). (1924). F. The Ziegfeld Follies [Tiyatro oyunu]. ABD: The New Amsterdam Theatre.

Old Fashioned Way. (2014, 5 Temmuz). Past Loveliness. https://oldfashionedway.tumblr.com/post/90831737868/costume-designed-by-travis-banton-forclaudette, Erişim Tarihi: 31 Ocak 2021

Porter, S. E. (Yönetmen). (1908). Pocahontas: A Child of the Forest [Film]. ABD: Thanhouser Company.

Roberts, A. ve Fisher, D. (1946). Put the Blame on Mame [Anita Kert Ellis tarafından kaydedilmiştir]. Gilda [Film müziği]. ABD: -

Shore, D. (Sunucu) \& Banner, B. (Yönetmen). (1956). B. Banner ve R. Wells (Yapımcılar), The Dinah Shore Chevy Show [Televizyon şovu]. ABD: NBC.

Sternberg von, J. (Yönetmen). (1930). Morocco [Film]. ABD: Paramount.

Sternberg von, J. (Yönetmen). (1931). Dishonored [Film]. ABD: Paramount.

Sternberg von, J. (Yönetmen). (1932). Shangai Express [Film]. ABD: Paramount.

Sternberg von, J. (Yönetmen). (1932). Blonde Venus [Film]. ABD: Paramount.

Sternberg von, J. (Yönetmen). (1934). The Scarlet Empress - Her Regiment of Lovers [Film]. ABD: Paramount.

Sternberg von, J. (Yönetmen). (1936). The Devil is a Woman [Film]. ABD: Paramount.

Travis Banton. (2001). Fashion Book (s. 32) Hong Kong: Phaidon. 
Truhler, K. (2013, 29, Ekim). Style Essentials: Travis Banton Transforms Clara Bow and Fashion Forever with 1927's IT. Glamamor. http://www.glamamor.com/2013/10/ style-essentials-travis-banton.html, Erişim tarihi: 31 Ocak 2021

Uhlirova, M. (2013). 100 Years of the Fashion Film: Frameworks and Histories. Fashion Theory, 17(2), 137-157. https://doi.org/10.2752/1751741 13X13541091797562

Vidor, C. (Yönetmen). (1944). Cover Girl [Film]. ABD: Columbia.

Vidor, C. (Yönetmen). (1946). Gilda [Film]. ABD: Columbia.

Viertel, B. (Yönetmen). (1932). The Man from Yesterday [Film]. ABD:Paramount.

Wikipedia. (2021, 25 Şubat). Marlene Dietrich Filmography. https:// en.wikipedia.org/wiki/Marlene_Dietrich_filmography. Erişim tarihi: 28 Şubat 2021 